\title{
The climatology of the Red Sea - Part 2: The waves
}

3 Sabique Langodan ${ }^{1}$, Luigi Cavaleri ${ }^{2}$, Angela Pomaro ${ }^{2}$, Yesubabu Vishwanadhapalli ${ }^{3}$, Luciana

4 Bertotti $^{2}$ and Ibrahim Hoteit ${ }^{1, *}$

$5 \quad{ }^{1}$ King Abdullah University of Science and Technology (KAUST), Physical Sciences and 6 Engineering Division, Thuwal 23955-6900, Saudi Arabia

$7 \quad{ }^{2}$ Institute of Marine Sciences, Venice, Italy

$8 \quad{ }^{3}$ National Atmospheric Research Laboratory (NARL), Gadanki- 517 112, Andhra Pradesh, India. 9 10 mail: ibrahim.hoteit@kaust.edu. 


\section{Abstract}

20 The wave climatology of the Red Sea is described based on a 30-year hindcast generated using 21 WAVEWATCH III configured on a 5-km resolution grid and forced by Red Sea reanalysis 22 surface winds from the Advanced Weather Research Forecasting (WRF) model. The wave 23 simulations have been validated using buoy and altimeter data. The four main wind systems in 24 the Red Sea characterize the corresponding wave climatology. The dominant ones are the two 25 opposite wave systems with different genesis, propagating along the axis of the basin. The 26 highest waves are generated at the center of the Red Sea as a consequence of the strong seasonal 27 winds blowing from the Tokar Gap on the African side. There is a general long-term trend 28 toward lowering the values of the significant wave height over the whole basin, with a 29 decreasing rate depending on the genesis of the individual systems.

30

Key Words: The Red Sea, Wave climatology, Red Sea waves, Long-term climatological change 
Accurate knowledge of ocean surface weather conditions, particularly wind and wave, is important for a broad range of applications ranging from scientific studies, to engineering applications and industrial developments. While global studies (e.g., Hermer et al., 2010; Gulev and Grigorieva, 2004) provide an overview of the general wave climate, regional studies, such as Patra and Bhaskaran (2016) for Bay of Bengal, Gulev and Hasse (1999) for North Atlantic, Sasaki (2014) for North Pacific, and Casas-Prat and Sierra (2013) for Mediterranean, investigate the waves climate and their trends over specific regions. Despite being one of the important world's shipping routes, the Red Sea remains to be explored in terms of wind-wave climatology. maritime activities in the basin. Because of the scarcity of the measured data in this region, a wave climatology of the Red Sea based on a 30-year hindcast generated using WAVEWATCH III configured on a 5-km resolution grid and forced by Red Sea reanalysis surface winds from the Advanced Weather Research Forecasting (WRF) model.

\section{The Red Sea}

51 The Red Sea is an elongated basin covering the area between $12^{\circ}-30^{\circ} \mathrm{N}$ and $32^{\circ}-43^{\circ} \mathrm{E}$ (see

52 Figure 1). The basin has 2,250 km long, extending from the Suez and Aqaba narrow gulfs in the

53 North to the southern strait of Bab el-Mandeb, and connecting the Red Sea with the Indian

54 Ocean. The geological genesis has established both the submerged and external characteristics.

55 The overall average depth is $490 \mathrm{~m}$, with a maximum depth below 2,000 m.

$56 \quad 2.1$ The wind 
57 The Red Sea is surrounded by a topography that determines much of its wind characteristics. The

high mountains on both sides of the Red Sea constrain the winds to blow along the axis of the basin. The dominant wind blows from northwest throughout the year over the northern Red Sea and Gulf of Suez, frequently extending to the southern strait. This wind is generally related to Mediterranean storms reaching the most eastern part of this basin. From May to October, northwest winds dominate the whole basin. During winter months (November to February), the northeast monsoon blows intensively over the Arabian Sea. In the Gulf of Aden, high mountains on both African and Arabian sides deviate the monsoon winds to blow through the Bab el Mandeb strait, leading to a southeast wind in the Red Sea. These southeast winds converge with the dominant northwest winds over the northern part of the Red Sea to create a convergence area centered around $18^{\circ} \mathrm{N}$, known as the Red Sea Convergence Zone (RSCZ). The topographic features surrounding the basin, with larger and smaller valleys cutting across the bordering mountain ridges, leads to typical local winds relevant for characterizing the local wind regimes. In summer (from May to September), the most relevant one is the wind blowing through the 110 $\mathrm{km}$ wide Tokar Gap located around $18^{\circ} \mathrm{N}$ on the African side. The wind blowing through the Tokar Gap is a synoptic-scale wind forcing regime associated with the Indian summer monsoon, further enhanced by the strong land-sea breeze (Jiang et al., 2009; Davis et al., 2015; Yesubabu et al., 2016). Finally, some narrow valleys on the Arabian side in the northern Red Sea lead to occasional localized jets. In a companion paper, Langodan et al. (2017, henceforth L1) provide a detailed description of the general wind patterns in the basin, discussing different characteristics of the various wind systems in terms of their climatology and their possible long-term trends.

To have a complete picture over the whole year, we emphasize that we have stressed the winter and summer conditions because it is during those two periods that intense phenomena occur in 
80 the Red Sea. The two intermediate transient seasons, spring and fall, are with milder wind

81 systems. Though wind bursts arrive from the Mediterranean during those periods with a lower

82 intensity compared to the winter, they do not meet with the southeast monsoon connected wind

83 and waves.

$84 \quad 2.2$ The waves

85 In this paper we are concerned with the climatology of the waves in the Red Sea and, as

86 expected, these react according to the wind patterns described in the previous section. The four

87 dominant wave systems are (see Figure 1 and also Table 1):

881 - Waves generated by the northwest winds that propagate in the southeast direction, frequently

89 reaching the Bab el Mandeb strait. These waves are marked as E1.

902 - Opposite to E1, waves propagating in the northwest direction from the Bab el Mandeb strait.

91 These waves are generated by the northeast monsoon winds and marked as E2.

923 - Waves generated by the Tokar Gap winds. On average, these waves are the most intense 93 events in the Red Sea, marked as E3.

944 - Locally generated waves by the mountain gap jets in the northern part of the Arabian 95 Peninsula, marked as E4. These waves are hardly relevant, being also often masked by the E1 96 system.

97 In the winter months, an interesting interaction takes place between systems E1 and E2. 98 Langodan et al. (2015) provide a detailed description of this situation and its implications. In this 99 period the systems E1 and E2 are active at the same time with almost equal wavelengths. These 100 wave fields are created by two different systems and, as specified, they occur in winter: the 101 monsoon connected southeast wind generates a wave field that extends much towards the north 
and a storm pulse enters from the Mediterranean Sea creating a cold front advancing along the Red Sea. This leads to very peculiar situation of the encounter of two opposite wind, and active wave systems. The convergence at the center of the Red Sea causes a full reversal of the winds coming from the north, which in turns causes warmer air from the south to slide on top of the colder air from the north. This leads to an area of cloudiness and drizzle in the middle of the otherwise sunny zone. On the surface, the convergence of the northwest and southeast wind systems lead to a unique situation of opposing wind-wave systems. Langodan et al. (2015) have shown how the usual wave model physics (see, e.g., Cavaleri et al., 2007) do not well describe the evolution of waves under this situation. They have proposed a correction term to the wind input and white-capping terms, somehow generalizing the standard formulation. This term has not been used in the present 30-year hindcast because not sufficiently tested under all possible conditions. Physically relevant, the implications of the "encounter" condition, limited in space and time, is marginal for the overall statistics.

Complementing the L1 companion paper on the wind climatology, in this paper we report the corresponding results for wind-waves in the Red Sea. Towards this aim, Section 3 describes the modeling system, the general hindcast procedure, and the data generated for the analysis. Section 4 offers a description of the wave climatology of the Red Sea, focusing on both the statistical aspects and the physics behind it. Taking advantage of the 30-years of the wave hindcast, in Section 5 we explore the presence of possible trends in time. Given that the waves are an integrated effect of the driving winds in space and time, the information provided by waves has a more general significance than the one reported by wind in the companion L1 paper. All our results are discussed and summarized in the last Section 6. 
124 Considering the companion paper (part 1) on wind climatology, dealing obviously with wind, in 125 this paper we encounter the problem of two opposite conventions for direction: coming from for 126 wind (meteorological one) and flowing to for waves (oceanographic one). Following the 127 suggestion of one anonymous reviewer, we considered using the same convention for both wind 128 and waves. We feel that such a solution would not be physical (e.g., a south coming wind creates 129 waves that, important for waves they propagate, are flowing north). We address, as well as we 130 could, the problem being as explicit as possible by referring most of the time to the E1, E2, E3, 131 E4 systems defined above and represented in Figure 1.

\section{The modeling system, the hindcast and the data available}

We first provide a brief description of the 30-year hindcast of the driving wind fields. For a more complete description, the reader is referred to the companion L1 paper. The detailed description of the modeling systems is discussed in Langodan et al. (2016, henceforth L2).

The Advanced Weather Research and Forecasting model (WRF, see Shamrock et al., 2008) was implemented with two, two-way nested domains, with a high-resolution $10 \mathrm{~km}$ inner domain centered on our area of interest, the Red Sea (Yesubabu et al., 2016). The simulations were reinitialized daily from the ERA-Interim reanalysis (see Dee et al., 2011) and the available observations were assimilated at 6-hour intervals. The outputs were made available at hourly intervals. The quality of the generated wind fields was verified versus buoy and scatterometer measured data. L2 reports low bias $\left(-0.07 \mathrm{~m} \mathrm{~s}^{-1}\right)$ and root-mean-square (rms) errors $\left(1.03 \mathrm{~m} \mathrm{~s}^{-1}\right)$, making the data suitable for forcing the wave model in the Red Sea.

The 30-year hourly wind fields have been used as input to force the third generation WAVEWATCH III wave model (version 4.18 and package ST4, Tolman, 2014). The model was implemented on a regular latitude-longitude grid with $0.05^{\circ}$ resolution. We used 29 frequencies, 
147 starting from $0.05 \mathrm{~Hz}$ with 1.1 geometric progression and 36 equally spaced directions. The 148 integrated parameters, such as significant wave height $H_{s}$, mean and peak periods $T_{m}, T_{p}$, and 149 mean direction $\theta_{\mathrm{m}}$, were saved at hourly intervals.

150 The outputs were validated versus buoy and altimeter data. The buoy (WMO 23020, location is 151 marked in Figure 1) was deployed from October 2008 till May 2010. All the available altimeter 152 (ERS-1, ERS-2, Jason1, Jason2, GFO, Envisat, Cryosat2, Altika) data were used $\left(\sim 4 \times 10^{5}\right.$ 153 collocated points), as derived from the GlobWave database (http://www.globwave.org). Table 2 154 reports the general performance of the wave model when compared to these data (only buoy 155 observations were available for wave period and direction). Bias and scatter index are 156 respectively defined as

158 where $M_{i}$ and $O_{i}$ represents the model data and observations, and

$$
\text { Scatter Index }=\frac{R M S E}{\bar{O}}
$$

159 where $\bar{O}$ is the average value of observations, and RMSE is defined as $\sqrt{\frac{\sum_{i}\left(M_{i}-O_{i}\right)}{n}}$.

161 In general, the errors (which include also the instrument errors) are small enough to be confident 162 about the derived general climatology. A particularly large value is found in the directional rms 163 error. This points to the frequent superposition of different, possibly opposite, wave systems (at 164 the buoy position) and the consequent sensitivity of the direction. This likely leads to an 165 increased error compared to errors in the case of single systems. The associated very small bias 
166 suggests again good confidence in the overall results, especially to investigate long-term 167 statistics.

168 To summarize, we have available 30 years of wave data at a resolution of $0.05^{\circ}$ in space and one-

169 hour in time. This corresponds to more than $2.6 \times 10^{5}$ data (for $H_{s}, T_{m}, T_{p}, \theta_{m}$ ) per grid point. We 170 used this information to derive the wave climatology of the Red Sea.

\section{4. The wave climatology}

172 For the Red Sea wave climatology, we first provide a general overview of the wave conditions

173 related to the winds described in L1. Then we highlight the spatial and temporal differences 174 between three areas, respectively northern, central, and southern (for convenience henceforth $\mathrm{N}$, 175 C, S) parts of the Red Sea. The two dash lines in Figure 1 split the basin accordingly. While 176 some characteristics are common throughout the basin, each of these three areas has specific 177 characteristics that will be soon detailed.

178 Figure 2 provides the general distribution of the mean and maximum significant wave height, in 179 the summer (panels a and b) and the winter months (panels c and d), respectively. In these 180 figures, the color bars represent different parameter ranges and for each point, the maximum 181 refers to the highest value in the whole 30-year time series. The general distribution of mean $\mathrm{H}_{\mathrm{s}}$ 182 values in most parts of the basin in summer manifests the dominant role of the meteorological 183 inputs from the Mediterranean Sea. The exception is the most southern part of the basin, 184 suggesting that these impulses are in general not strong enough to reach this area (more than $1852000 \mathrm{~km}$ away from the northern end). Note that the highest waves in the basin are produced by 186 the Tokar Gap winds in summer. An interesting oceanographic detail is the different positions of

187 the two larger waves areas in panels $2 \mathrm{a}$ and $2 \mathrm{~b}$. The reason is the different behavior of fetch188 limited wind-generated waves under a compact jet that expands with decreasing wind speeds 
while funneling out to the sea. In "normal" conditions, the expansion is more limited and dependent on both wind speed and fetch; a maximum wave height is reached at a certain distance

191 from the coast. In contrast, particularly in strong wind cases, the waves grow correspondingly 192 faster and the peak is reached sooner, i.e. for a shorter fetch, the rapid wind speed decreases with 193 distance because of the wider expansion of the jet. Another factor could be the occasional 194 encounter between a northerly storm (cited above) and the Tokar Gap winds. The latter situation 195 is practically a daily event in summer over the central part of the basin.

196 The major difference between summer and winter is the presence, in the latter, of high waves in 197 the most southern part of the Red Sea. These are generated by the northeast monsoon connected 198 southern winds, which prevail throughout the season but without reaching extreme values. This 199 leads to relatively high waves in Figure 2c compared to the maxima in Figure 2 d. In the 200 southeastern Red Sea, the waves are significantly attenuated by the islands, in particular coral 201 reefs. This also results in a well-defined preferential flux of energy along the main axis of the 202 Red Sea, with swell characteristics most of the time as a consequence of the frequent propagation 203 of waves from the north (E1).

204 For a more integral view, we show in Figure 3 the statistical distribution of $H_{s}$ in the cited three 205 areas of the basin (see Figure 1). In area N, the waves height range between one and two meters, 206 with the highest waves generated by the frequent northerly storms. Areas $\mathrm{C}$ and $\mathrm{S}$ are 207 progressively more concentrated on the relatively low wave heights, less than one meter. 208 However, for the highest range $(>2.25 \mathrm{~m})$, more occurrences are observed in area $\mathrm{C}$, as a result 209 of the occasionally very strong Tokar Gap winds, especially when superimposed to a northerly 210 event. 
211 A much more illustrative representation of the wave conditions in the Red Sea is given in Figure

2124 , where we plot the variability of the $95^{\text {th }}$ and $5^{\text {th }}$ percentiles (the upper and lower borders of the 213 grey area), the daily mean, and the corresponding 31-day running average of waves in the three 214 zones N, C and S. Although the waves in N exhibit some variability throughout the year, the 215 maxima $\left(95^{\text {th }}\right.$ percentile) are relatively more observed within the first part of the year (January216 March), but without being much different from the other periods. A minimum in the $95^{\text {th }}$ 217 percentile is reached in the summer months, due to both reduced activity in the Mediterranean 218 Sea, and to the absence of the, albeit small, waves from the south during this period. The 219 prominent feature of area $\mathrm{C}$ is the intense waves generated by the Tokar Gap winds in summer. 220 Otherwise the wave climate in this area is dominated by the superposition of waves coming from 221 north and south. The noticeable feature in $\mathrm{S}$ is related to the northeast monsoon period, from 222 October to April. The means and the 5 percentiles are consistent, of course at a reduced level, 223 with the 95 one. The partial exception is the summer Tokar Gap values in C, the largest increase 224 of the maximum values (95 percentiles) representing the peculiar physics (may be related to the 225 non-linearity) of these events in the most intense cases.

226 The characteristics of winds associated with the four dominant meteorological systems, hence 227 waves, appear more clearly in the time series of the monthly values, respectively for $95^{\text {th }}, 50^{\text {th }}$ 228 and $5^{\text {th }}$ percentiles as shown in Figure 5. Consistent with Figure 4, the $\mathrm{N}$ waves are very 229 irregularly distributed throughout the year. Although the highest waves are observed in winter, 230 the summers too show high waves in the time series, not much different from the winter periods. 231 The yearly cycle is more evident in $\mathrm{C}$ and $\mathrm{S}$. The differences between the $95^{\text {th }}$ and $50^{\text {th }}$ 232 percentiles in $\mathrm{C}$ are the characteristic of a temporary phenomenon. The Tokar Gap wind blows 233 only for part of the day, preferably in the morning hours, which explains this large difference. In 
$234 \mathrm{~S}$ waves, the difference between the $95^{\text {th }}$ and $50^{\text {th }}$ percentiles is rather variable (note the high $50^{\text {th }}$ 235 percentile values in 1999 and 2002), reflecting the variable characteristics of the monsoon from 236 year to year.

237 Another basic feature of the wave characteristics in the three zones emerges from their $\mathrm{H}_{\mathrm{s}}-\mathrm{T}_{\mathrm{m}}$ 238 statistical distributions as shown in Figure 6. The two dotted lines correspond to the 1/15 and $2391 / 25$ wave slopes. The first value of the isolines is higher than usually found in deep waters 240 because we have used $T_{m}$ instead of $T_{p}$. This choice was mandatory due to the mixed character of 241 the waves, wind-sea and/or swell, in parts of the basin. Isolines are at ratio of 2, geometric 242 progression starting from 0.025 .

243 In $\mathrm{N}$, the distribution of waves reflects the basic local feature of a wind-sea. A slight prominence 244 in the upper left of the distribution represents some low waves coming from large distance, i.e., 245 low wave heights with relatively large periods coming from the southern Red Sea (E2). This 246 feature is more evident in $\mathrm{C}$, due to the waves coming from both north and south. Moreover, the 247 distribution extends towards the high values (Tokar Gap waves, E3). The influence of the waves 248 propagating from north (E1) is much more evident in $\mathrm{S}$, with the large bump of low wave heights 249 and larger periods.

250 The above frames well the main characteristics of the wind-waves in the Red Sea. However, with 251 the exception of what can be seen in Figure 5, we do not have information about how these 252 characteristics change in time. This is discussed in the next section.

\section{5. The climatic trends}

254 Similar to the discussion of Figure 3, we begin with an integral view showing the statistical 255 distribution of the significant wave height for the first (1985-1994) and last decades (2005-2014) 
256 of the studied period (Figure 7). We stress that the results for the intermediate decade are fully

257 consistent with the ones we report here. We chose to discuss only the extreme decades to obtain

258 larger quantities and put more emphasize on differences. We use a logarithmic scale for a better

259 representation of the differences in the higher $\mathrm{H}_{\mathrm{s}}$ range $(2-4 \mathrm{~m})$. This comparison clearly

260 indicates a general shift of the wave heights towards lower values. Otherwise discrepancies in

261 the higher value range are not significant because of the limited number of samples.

262 As a further step toward understanding the change in wave climate, Figure 8 provides the spatial

263 distribution of the trend $\left(\mathrm{cm} \mathrm{y}^{-1}\right)$ of a) the full time series $\left(\sim 2.6 \times 10^{5}\right.$ data for each point of the

264 basin), b) the monthly maxima (360 data), c) the monthly $90^{\text {th }}$, and d) $50^{\text {th }}$ percentiles. Again

265 there is an obvious decreasing trend of the wave height and its distribution is reflected

266 throughout the basin. It is also noticeable from Figure 8 that the rate of decrease is consistent

267 with, if not proportional to, the $\mathrm{H}_{\mathrm{s}}$ distribution.

268 To further explore these results and to understand the rate of decrease of the dominant wave 269 systems, we have evaluated the trend in the $\mathrm{H}_{\mathrm{s}}$ for the three $\mathrm{N}, \mathrm{C}$, and $\mathrm{S}$ areas. We have first used 270 the Mann-Kendall approach (Mann, 1945; Kendall, 1975), then quantified the trend using the 271 Sen (1968) method. Pomaro et al. (2017) provide a full description of the procedure.

272 Evaluating the trend in $\mathrm{H}_{\mathrm{s}}$ for each month from January (1) till December (12) emphasize the 273 possible seasonality and the genesis of these trends. The results are shown in Figure 9 for the $27499^{\text {th }}, 95^{\text {th }}, 75^{\text {th }}$, and $50^{\text {th }}$ percentiles. A circle indicates those with greater than $90 \%$ significance.

275 As expected, the trends are almost everywhere negative; the only exception being the $99^{\text {th }}$ 276 percentile result for September in C. Though the decrease is very diffused, very clear patterns 277 emerge. For example, the decrease in the first months of the year are more pronounced in $\mathrm{C}$ than 278 in $\mathrm{N}$ (and only mild in S). These indicate a reduced intensity of the Mediterranean intrusions 
279 (E1), which prevent the storm from reaching the southern Red Sea. This is confirmed from the trends at $\mathrm{S}$ and it seems proportionally more marked for the higher percentiles, indicating most

281 severe events. With the exception of the $99^{\text {th }}$ percentile of the waves in C in September, there is no significant trend in this period, which cannot be interpreted in a specific direction.

284 observed trend. For this purpose, and focusing on the E1 and E2 systems (see Table 1), we have repeated the analysis, but considering separately the south (E1) and north (E2) going systems.

286 More specifically, we have considered the time series of wave data whose mean flow direction is 287 within a $90^{\circ}$ sector centered about the Red Sea main axis, respectively between $112.5^{\circ}$ and $202.5^{\circ}$ for south going waves (referred as D1), and between $292.5^{\circ}$ and $22.5^{\circ}$ for north going waves (referred as D2). It is evident that D1 and D2 are likely to be similar to E1 and E2. The corresponding results are given in Figures 10 and 11, respectively. A decreasing tendency in the

291 intensity of the E1 system is evident in D1. For instance, as already pointed out, the strong 292 decrease in S during February points to a progressively reduced capability of the E1 system to 293 extend up to the most southerly part of the basin. Partially, this trend is also noticeable in 294 December, at least clearly observed in C. In contrast, the indications are scarcer for D2 as shown 295 in Figure 11. Note that a missing value in the plot means that there were not enough data to 296 compute a meaningful statistics for that particular month. There is no observed significant trend 297 in the data, except for wave heights in the last months of the year, related to the northeastern 298 monsoon generated waves.

299 To summarize the results from this section, we have found a substantial decrease of the storms 300 related to the intrusions from the Mediterranean Sea (E1). A possible similar tendency for the 301 Tokar Gap waves (E3) and a much-reduced similar signal for the northeastern monsoon 
302 connected wind generated waves (E2) are also observed. We have not explored E4, the narrow 303 jets due waves in the northern part of the basin because of their reduced relevance, and 304 consequent masking of the possible signal by the E1 system.

\section{Summary and discussion}

306 We summarize here the main characteristics of the wave climate in the Red Sea.

3071 - Three wave systems dominate in the basin: the most prominent one occurring in the 308 northwest (E1) and associated to the intrusion of relatively cold air from the Mediterranean Sea, 309 the northward propagating waves (E2) forced by the orographically driven northeast monsoon 310 winds, and the waves (E3) that follow the Tokar Gap winds through the valley in the central part 311 of the African side. Figure 1 clearly depicts the situation.

$3122-$ E1 occurs practically throughout the year and the intrusions of relatively cold air from the 313 Mediterranean may have different origins in the summer and winter seasons. This wind leads to 314 higher waves (frequently $>2 \mathrm{~m}$ ) in the northern part of the Red Sea, which propagate southward 315 with progressively decreasing height. The non-straight coasts of the Red Sea lead to shadowing 316 areas, especially in the southern zone where the E1 waves mostly reduce to swell and exhibit a 317 more unidirectional propagation.

3183 - The E2 system, directed northwest and associated to the northeast monsoon, is present only 319 in the corresponding period, i.e. from October to April. It does not lead to large wave heights, but 320 to a rather consistent average value in time during the active period. The waves propagate in the 321 basin, but their influence decreases rather rapidly moving north.

3224 - The third system E3, associated with the Tokar Gap winds, generates the highest waves in 323 the Red Sea, also because its impulses often interact with the north coming waves. 
$3245-$ A fourth wave system (E4) is associated to the narrow valley jets present in the northern part

325 of the Arabian coast.

3266 - System E1 has no specific seasonality, while systems E2 and E3 have well defined periods of

327 action: E2 from October to April and E3 from July to September.

3287 - Red Sea waves exhibit locally generated character as more dominant in the north and more 329 seasonally in the central parts of the basin. But they are frequently a mixture of waves coming 330 from a distance (swell from north, E1) and locally generated (from south, E2) in the most 331 meridional part of the basin.

3328 - There exists a general decreasing trend in the overall wave heights of the Red Sea. This 333 decrease appears stronger for E1, milder for E2, and is also present in E3. The E4 signal is 334 submerged in the E1 and, in any case, of low relative importance.

335 Derived from an extensive and well-verified reanalysis, the above results are robust both in their 336 climate and trends in time (wherever significant). The local tendencies are connected to larger 337 scale changes and the obvious example is the decrease of the northerly storms as a consequence 338 of the progressively reduced wind (and wave) activity in the Mediterranean Sea (see, e.g., Conte 339 and Lionello, 2013). Though it might be more difficult to study, one may also consider 340 investigating this relationship from the other angle; once the physical connection between the 341 systems has been established, use the acquired, or measured, information at a relatively local 342 scale (the Red Sea in our case) to infer knowledge about the larger scales (climate). More work is 343 still needed to understand this relationship in the Red Sea, which requires a dedicated analysis 344 separating all the possible systems in the wind and wave fields.

\section{Acknowledgements}


346 King Abdullah University of Science and Technology (KAUST) funded this research. This 347 research made use of the resources of the Supercomputing Laboratory and/or computer clusters 348 at KAUST. Luigi Cavaleri has been partly supported by KAUST during his visits for research 349 collaborations. We express our appreciation for the extensive review of Robert Jensen and of 350 another anonymous reviewer. 


\section{References}

Casas-Prat M, Sierra JP. 2013. Projected future wave climate in the NW Mediterranean Sea. J. Geophys. Res. Oceans, 118: 3548-3568, doi:10.1002/jgrc.20233.

Cavaleri L, Alves J-HGM, Ardhuin F, Babanin A, Banner M, Belibassakis K, Benoit M, Donelan M, Groeneweg J, Herbers THC, Hwang PAEM, Janssen PAEM, Janssen T, Lavrenov IV, Magne R, Jaak Monbaliu, Onorato M, Polnikov V, Resio D, Rogers WE, Sheremet A, McKee Smith J, Tolman HL, Van Vledder G, Judith Wolf, Ian Young, WISE Group. 2007. Wave modeling-the state of the art. Progress in Oceanography, 75: 603-674.

Conte D, Lionello P. 2013. Characteristics of large positive and negative surges in the Mediterranean Sea and their attenuation in future climate scenarios. Global and Planetary Change. 111:159-173, doi:10.1016/j.gloplacha. 2013.09.006.

Davis SR, Pratt LJ, Jiang H. 2015. The Tokar Gap jet: Regional circulation, diurnal variability, and moisture transport based on numerical simulations. J. Clim. 28(15): 5885-5907, doi:10.1175/JCLI-D-14-00635.1.

Dee D.P and co-authors, 2011. The ERA-Interim reanalysis: configuration and performance of the data assimilation system. Q. J. R. Meteorol. Soc. 137:553-597. doi: 10.1002/qj.828.

Gulev SK, Hasse L. 1999. Changes of wind waves in the North Atlantic over the last 30 years. Int. J. Climatol. 19: 1091-1117.

Gulev SK, Grigorieva V. 2004. Last century changes in ocean wind wave height from global visual wave data. Geophys. Res. Lett. 31: L24302, doi:10.1029/2004GL021040. 
372 Hemer MA, Wang XL, Church JA, Swail VR. 2010. Coordinated global ocean wave projections. Bull. Am. Meteorol. Soc. 91: 451-454.

Jiang H, Farrar JT, Beardsley RC, Chen R, Chen C. 2009. Zonal surface wind jets across the Red Sea due to mountain gap forcing along both sides of the Red Sea. Geoph. Res. Letters, 36: L19605. doi:10.1029/2009GL040008.

Kendall MG. 1975. Rank correlation methods, $4^{\text {th }}$ edition, ed. C. Griffin, $160 \mathrm{pp}$.

Langodan, S., Cavaleri, L., Viswanadhapalli, Y., Hoteit, I., 2015. Wind wave source functions in opposing seas. J. Geophys. Res. Oceans. 120: 6751-6768, doi: 10.1002/2015JC010816.

Langodan S, Cavaleri L, Viswanadhapalli Y, Pomaro A, Bertotti L, Hoteit I. 2017. The climatology of the Red Sea - part 1: The wind. Int. J. Climatol. (under review)

Langodan S, Viswanadhapalli Y, Dasari HP, Knio O, Hoteit I. 2016. A high resolution assessment of wind and wave energy potentials in the Red Sea. Applied Energy. 181: 244-255, doi: 10.1016/j.apenergy.2016.08.076.

Mann HB. 1945. Non-parametric tests against trends. Econometrica. 13: 63-171.

Patra A, Bhaskaran PK. 2016. Trends in wind-wave climate over the head Bay of Bengal region. Int. J. Climatol. doi:10.1002/joc.4627

Pomaro A, Cavaleri L, Lionello P. 2017. Characteristics and trends of the Adriatic Sea wind waves: analysis of a 37 year long instrumental dataset. Int. J. Climatol. (submitted for publication).

Sasaki W. 2014. Changes in the North Pacific wave climate since the mid-1990s, Geophys. Res. Lett. 41: 7854-7860, doi:10.1002/2014GL061590. 
393 Sen PK. 1968. Estimate of the regression coefficients based on Kendall's tau, J. of the Amer. Statistical Association, 63: 1379-1389, doi:10.2307/2285891.

395 Skamarock WC, Klemp JB, Dadhia J, Gill DO, Barker DM, Duda MG, Huang XY, Wang W, 396 Powers JG. 2008. A description of the Advanced Research WRF version 3, NCAR Tech. 397 Note NCAR/TN-475-STR, 113 pp. Nat. Cent. For Atmos. Res, Boulder, Colo.

398 Tolman HL. 2014. User manual and system documentation of WAVEWATCH-III version 4.18. 399 Technical Note Nr. 316, NOAA/NWS/NCEP/OMB.

400 Yesubabu V, Hari Prasad D, Sabique L, Srinivas CV, Hoteit I. 2016. Climatic features of the Red 401 Sea from a regional assimilative model. Int. J. Climatol. DOI: $10.1002 /$ joc.4865 


\section{Figure captions}

404 Figure 1 - The Red Sea. The two dash lines divide the basin in three logical zones where different winds and associate wave systems (arrows) dominate, albeit in different periods of the year. Note the bordering orography that strongly conditions the wind, hence waves, in the basins. The red dot shows the buoy position.

Figure 2 - Mean (panels a, c) and maximum $(b, d)$ significant wave heights distribution in the Red Sea. Left and right panels are for summer and winter, respectively. The color bars represent different parameter ranges

Figure 3 - Statistical distribution of the significant wave heights in the three regions indicated in Figure 1.

Figure 4-95 and 5 percentiles (borders of the grey area), mean and running average distribution of the daily significant wave height in the three regions indicated in Figure 1.

Figure $5-95,50$, and 5 percentiles of the monthly significant wave height along the 1985-2014 period.

Figure 6 - Statistical distribution of the significant wave height and mean period for each of the three regions indicated in Figure 1. Isolines are at a ratio of 2, geometric progression starting from 0.025 .

Figure 7 - As Figure 3, but for the two decades 1985-1994 and 2005-2014. A logarithmic scale is used.

Figure 8 - Spatial distribution of the significant wave height best-fit slopes for a) the full time series, b) the monthly maxima, c) the monthly 90, d) monthly 50 percentiles. 
424 Figure 9 - For each of the three zones delimited in Figure 1, north to south from top to bottom:

425

426

427

428

429

430

431

432

433

434

435 for each month of the year, 99, 95, 75, 50 percentiles of the long term trend of the significant wave height. A circle indicates that the result is significant at the $90 \%$ level.

Figure 10 - As Figure 9, but for the south going waves in a $90^{\circ}$ sector centered on the main axis of the basin.

Figure 11- As Figure 9, but for the north going waves in a $90^{\circ}$ sector centered on the main axis of the basin.

\section{Table captions}

Table 1 -The main wave systems in the Red Sea and their characteristics

Table 2 - Performance of the wave model against buoy and altimeter measured data 
436 Table 1 - The main wave systems in the Red Sea and their characteristics

\begin{tabular}{|l|l|}
\hline Wave system & Characteristics \\
\hline E1 & $\begin{array}{l}\text { Generated by winds blowing from the northern end towards the southern } \\
\text { part of the basin }\end{array}$ \\
\hline E2 & $\begin{array}{l}\text { Generated by the northeast monsoon connected winds blowing from } \\
\text { south to north in the basin }\end{array}$ \\
\hline E3 & Associated to the strong winds blowing through the Tokar Gap \\
\hline E4 & Associated to the narrow wind jets blowing from the north Arabian side \\
\hline
\end{tabular}

437

438 Table 2 - Performance of the wave model against buoy and altimeter measured data

\begin{tabular}{|c|c|c|c|c|}
\hline parameter & bias $\left(\mathrm{m}, \mathrm{s},{ }^{\circ}\right)$ & $\operatorname{rmse}\left(\mathrm{m}, \mathrm{s},{ }^{\circ}\right)$ & correlation & scatter index \\
\hline significant wave \\
height & 0.03 & 0.24 & 0.89 & 0.26 \\
\hline mean period & 0.41 & 0.83 & 0.70 & 0.19 \\
\hline mean direction & -4.3 & 38.7 & 0.66 & 0.30 \\
\hline
\end{tabular}




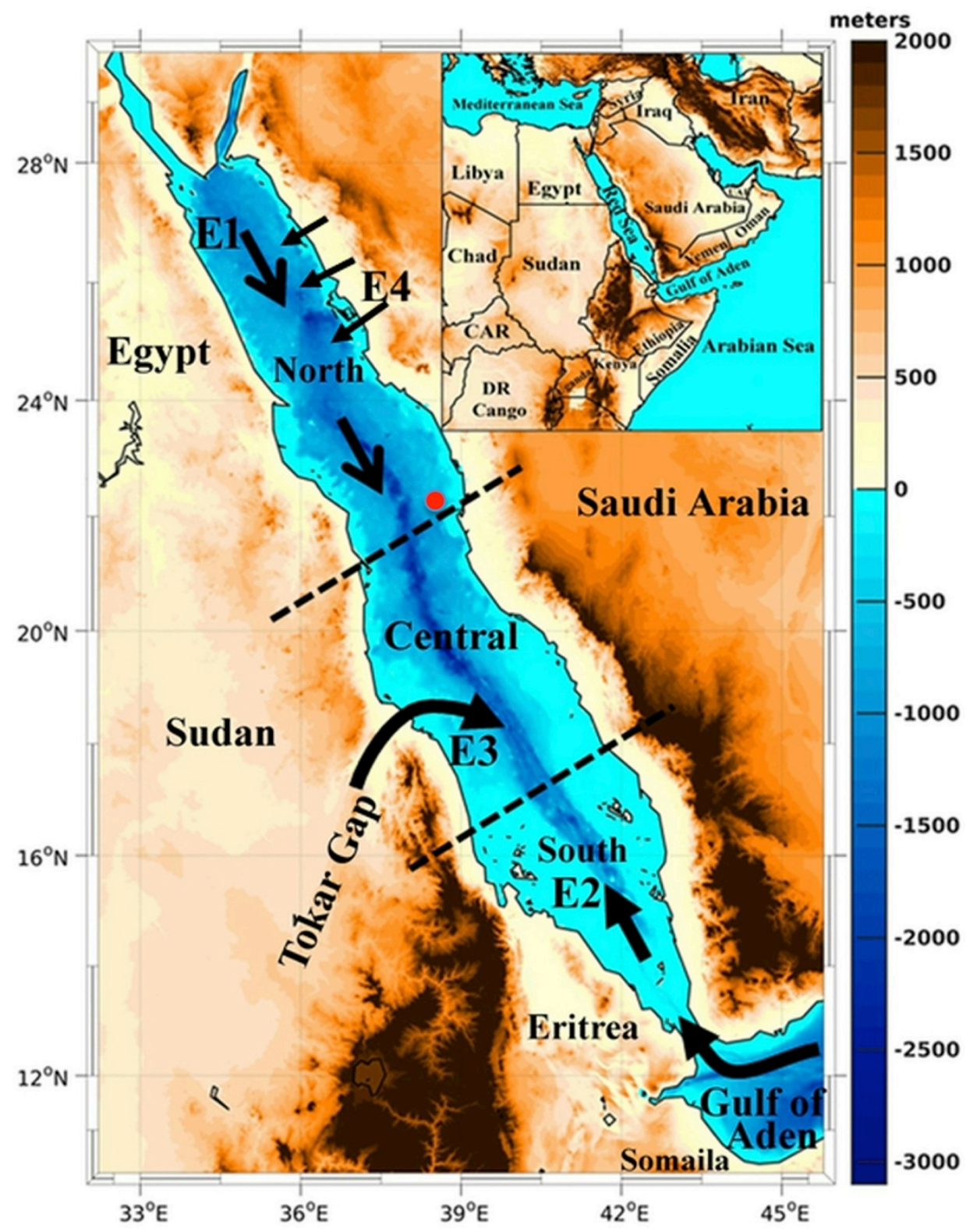

442 Figure 1 - The Red Sea. The two dash lines divide the basin in three logical zones where different winds and associate wave systems (arrows) dominate, albeit in different periods of the year. Note the bordering orography that strongly conditions the wind, hence waves, in the basins. The red dot shows the buoy position. 


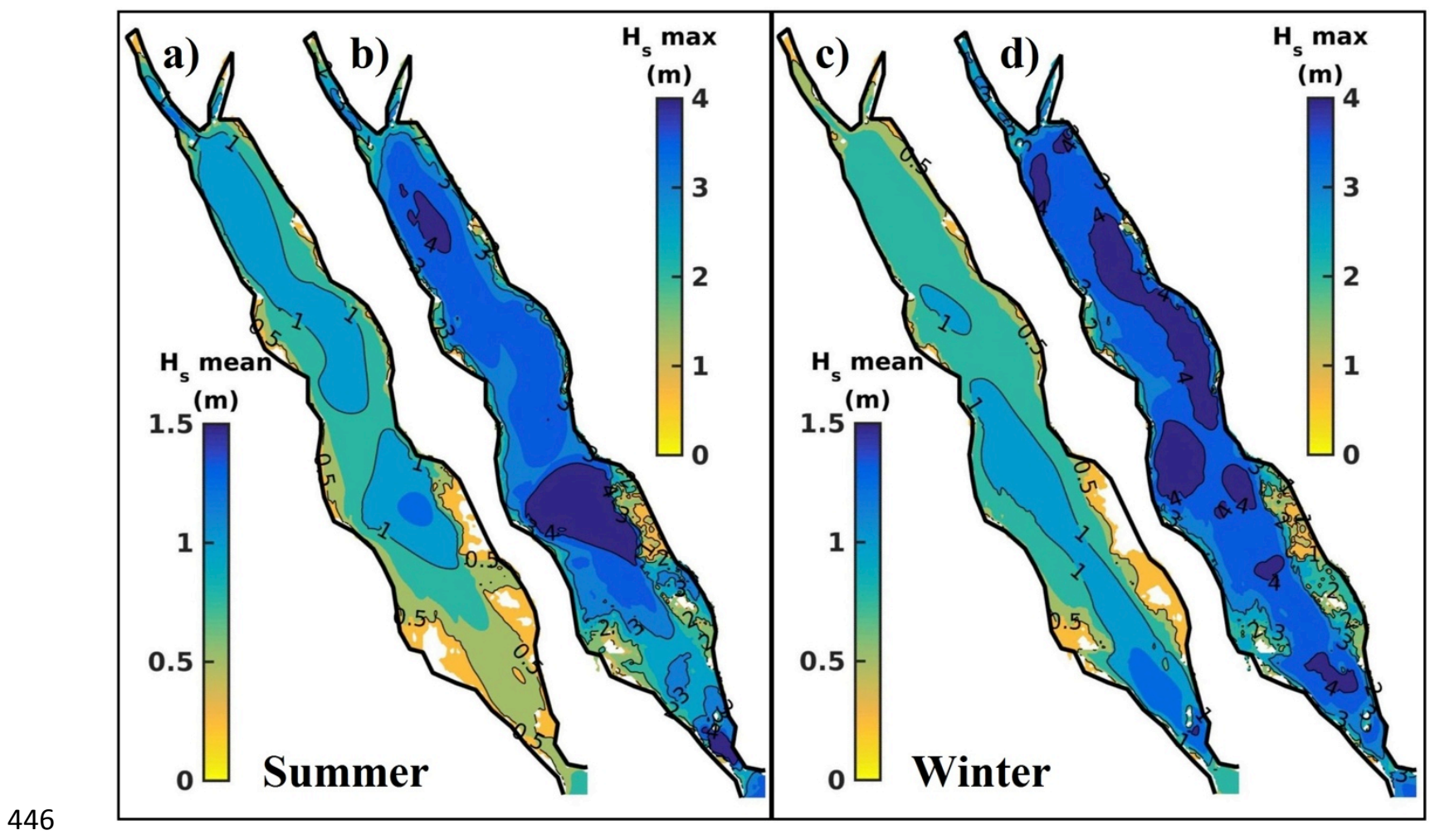

447 Figure 2 - Mean (panels a, c) and maximum (b, d) significant wave heights distribution in the

448 Red Sea. Left and right panels are for summer and winter, respectively. The color bars represent 449 different parameter ranges 


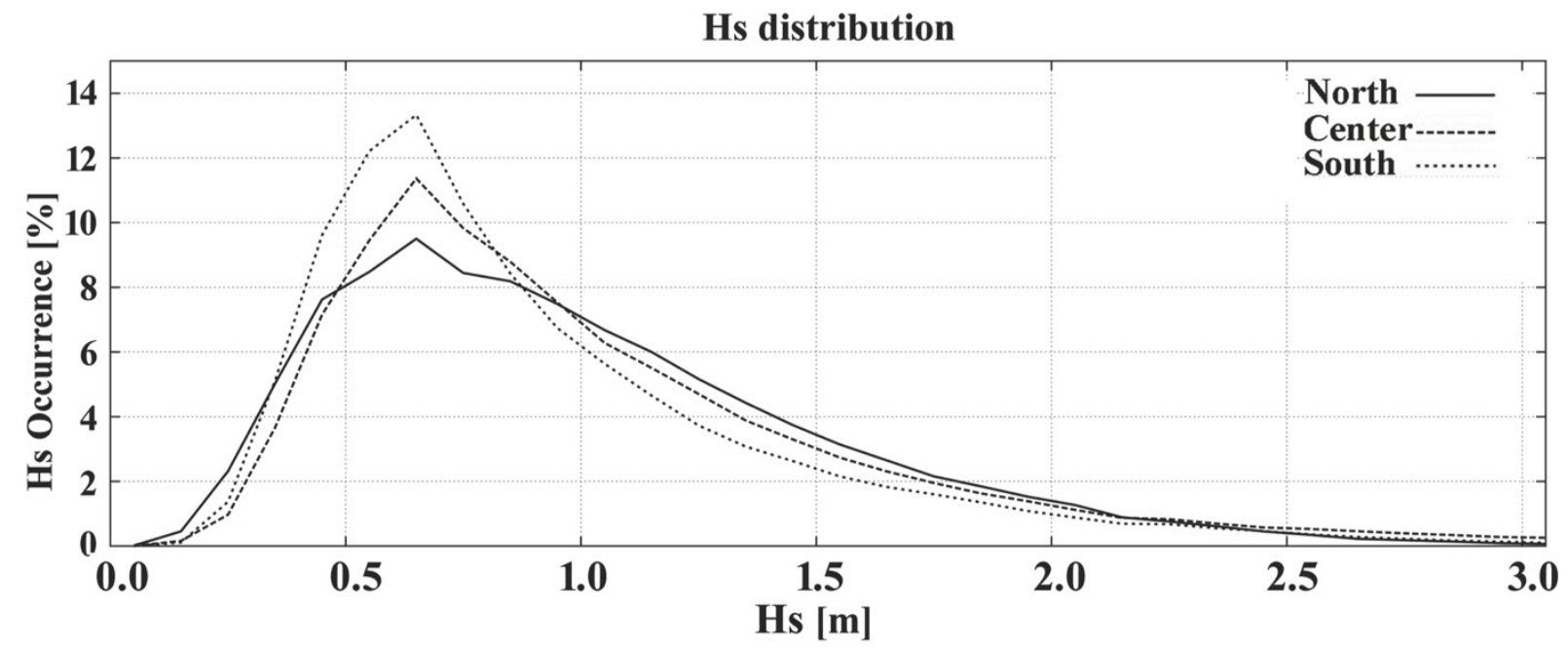

450

451

Figure 3 - Statistical distribution of the significant wave heights in the three regions indicated in

452

Figure 1. 

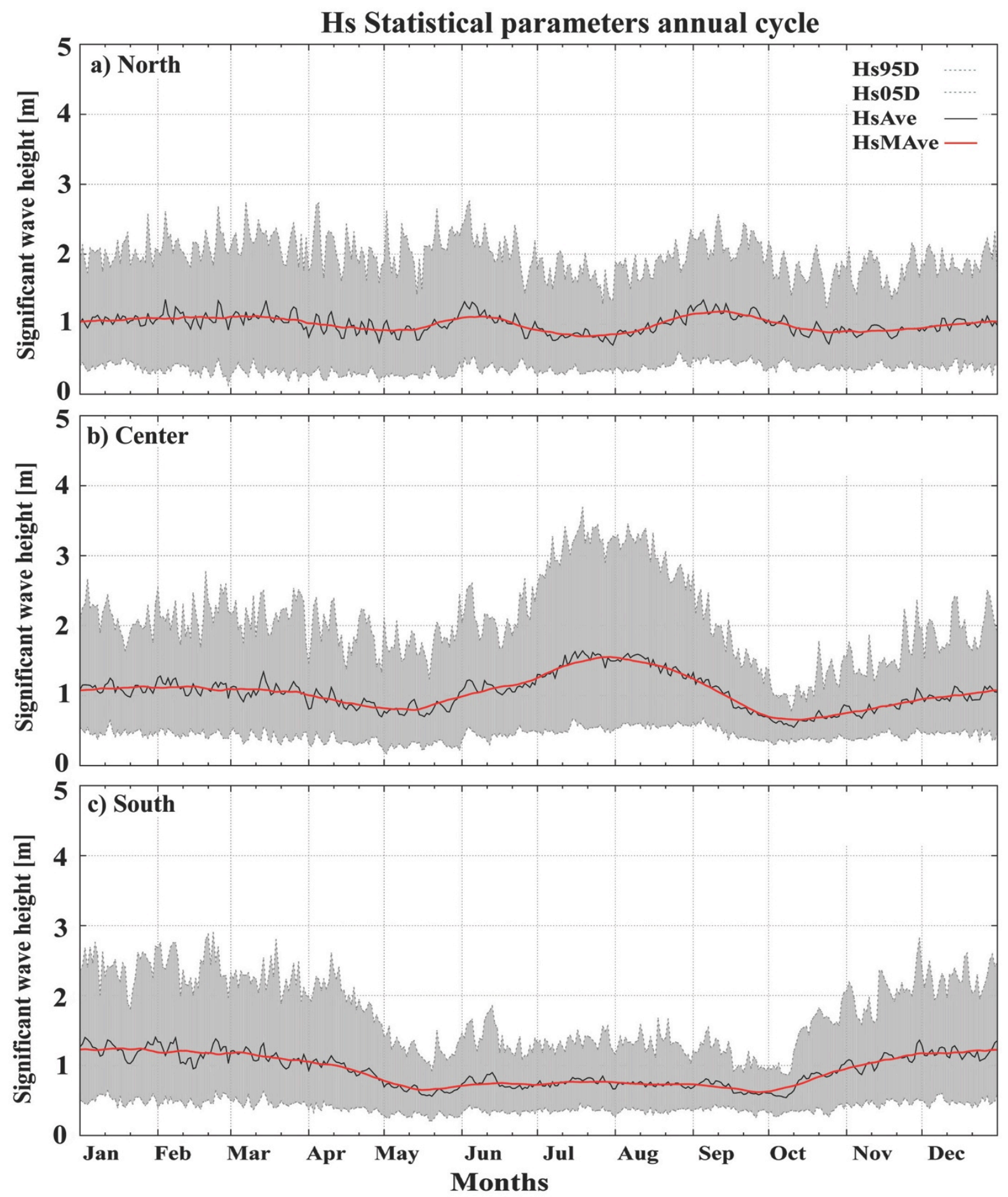

454 Figure 4-95 and 5 percentiles (borders of the grey area), mean and running average distribution of the daily significant wave height in the three regions indicated in Figure 1. 

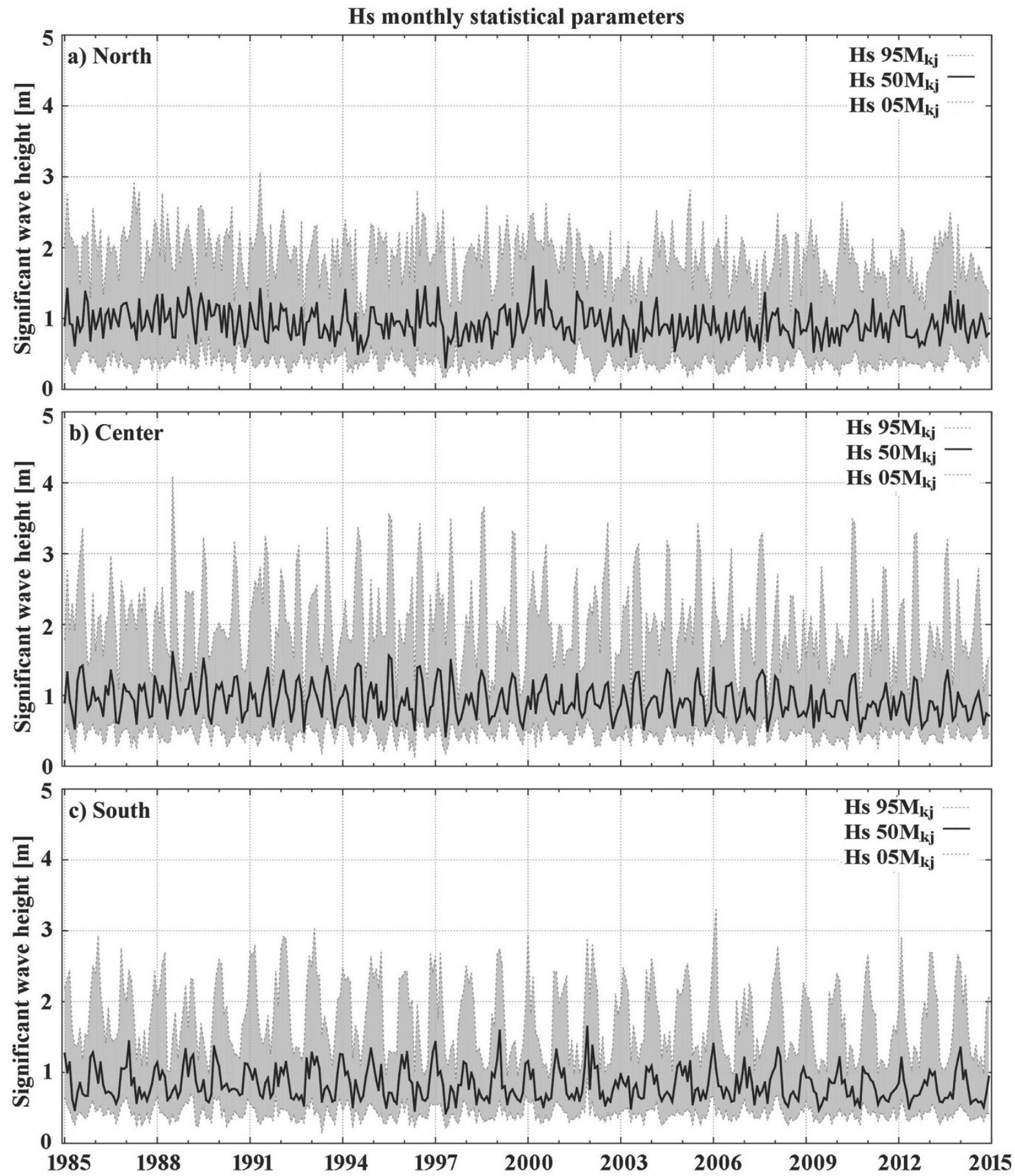

457 Figure $5-95,50$, and 5 percentiles of the monthly significant wave height along the 1985-2014 period. 

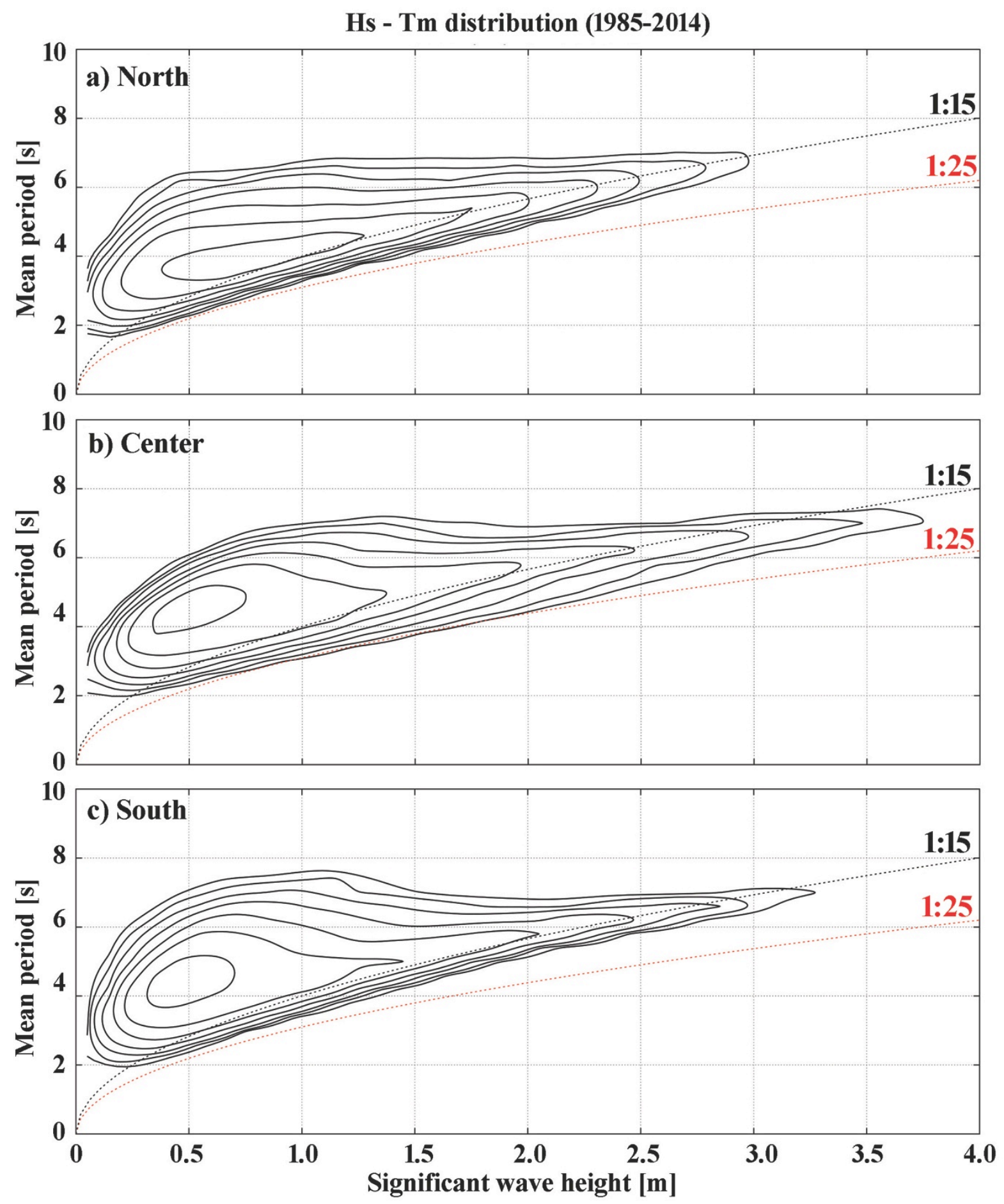

459

460 Figure 6 - Statistical distribution of the significant wave height and mean period for each of the

461 three regions indicated in Figure 1. Isolines are at a ratio of 2, geometric progression $462 \quad$ starting from 0.025 . 

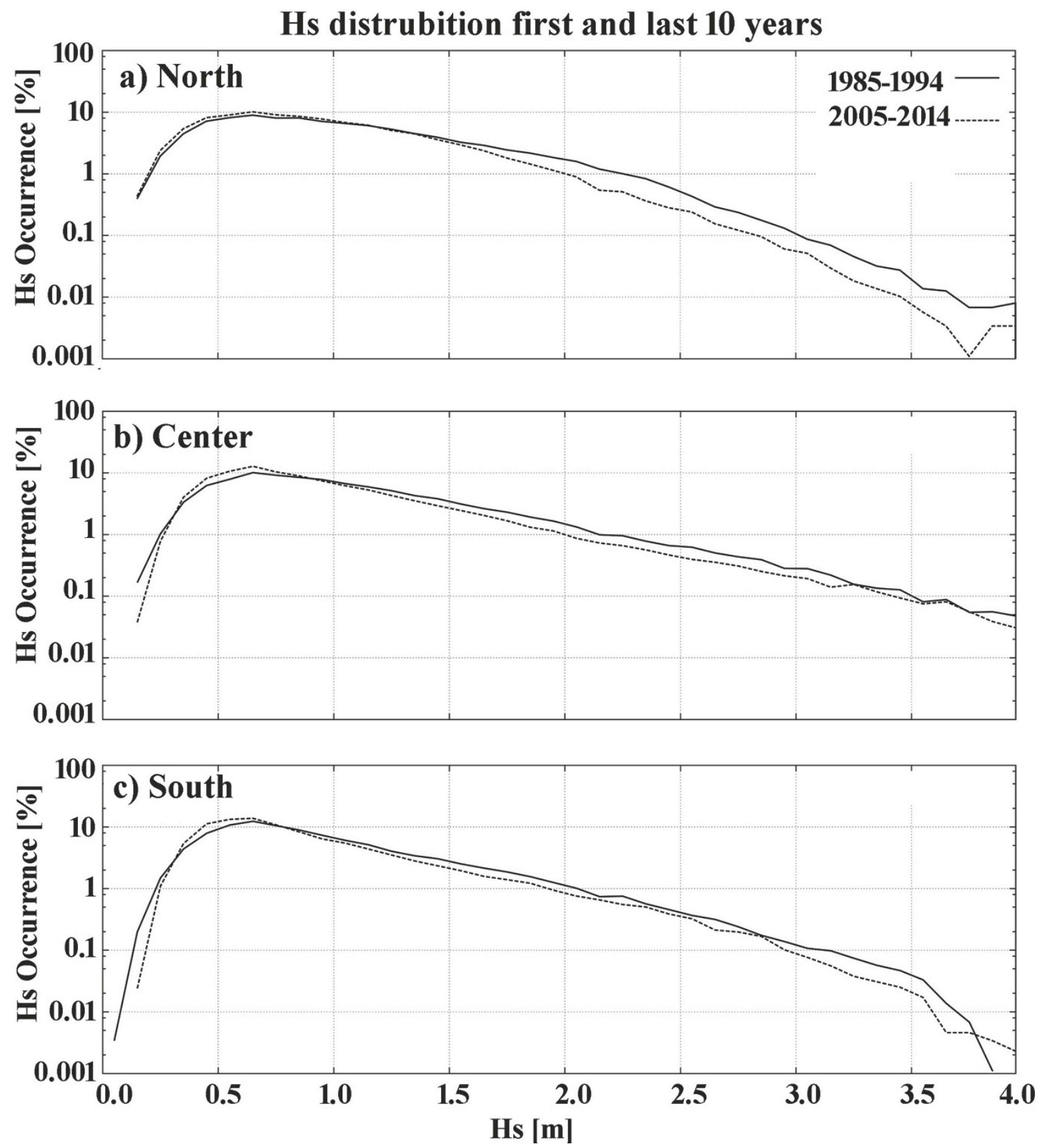

464 Figure 7 - As Figure 3, but for the two decades 1985-1994 and 2005-2014. A logarithmic scale 465 is used. 


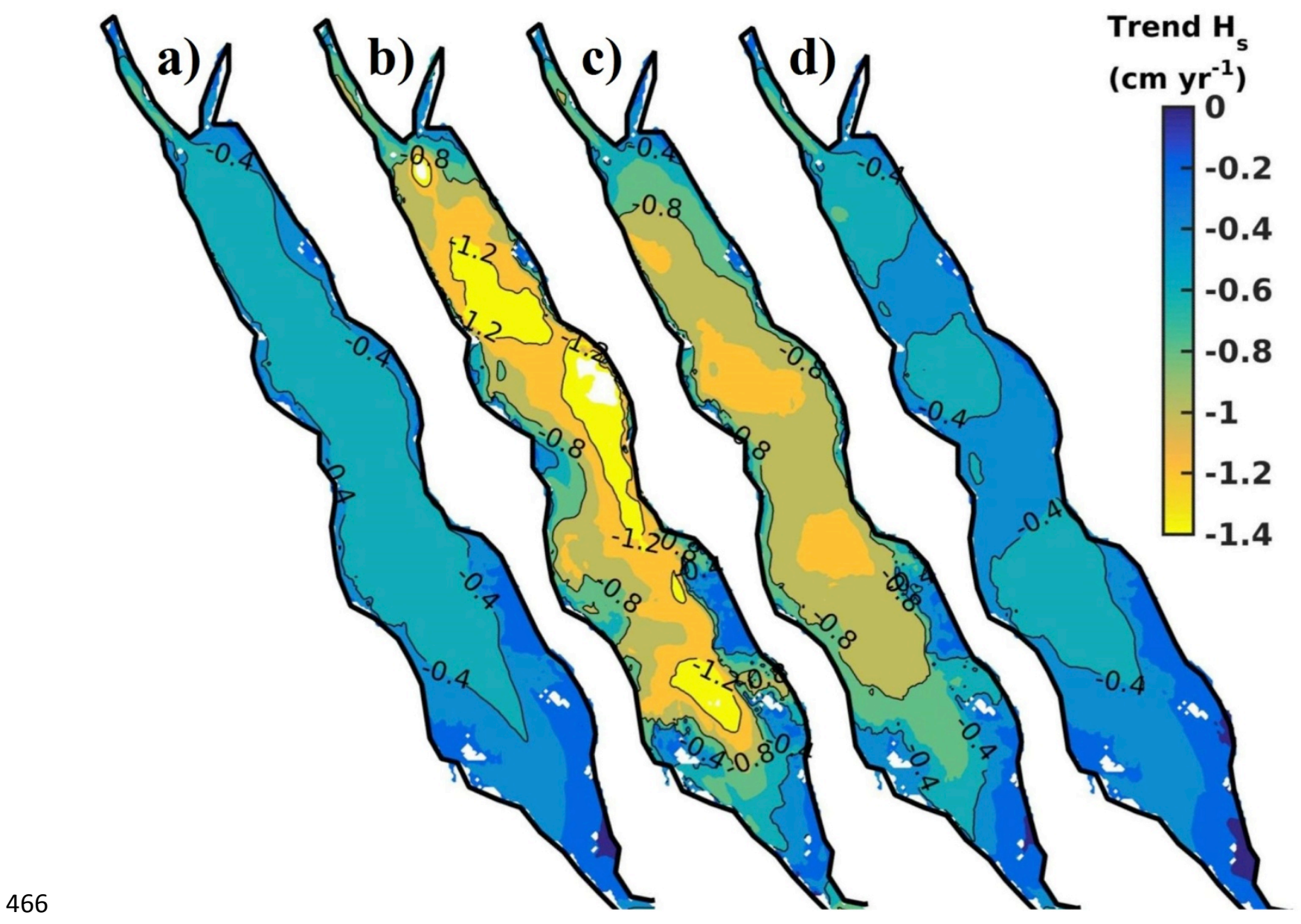

467 Figure 8 - Spatial distribution of the significant wave height best-fit slopes for a) the full time 468 series, b) the monthly maxima, c) the monthly 90 , d) monthly 50 percentiles. 

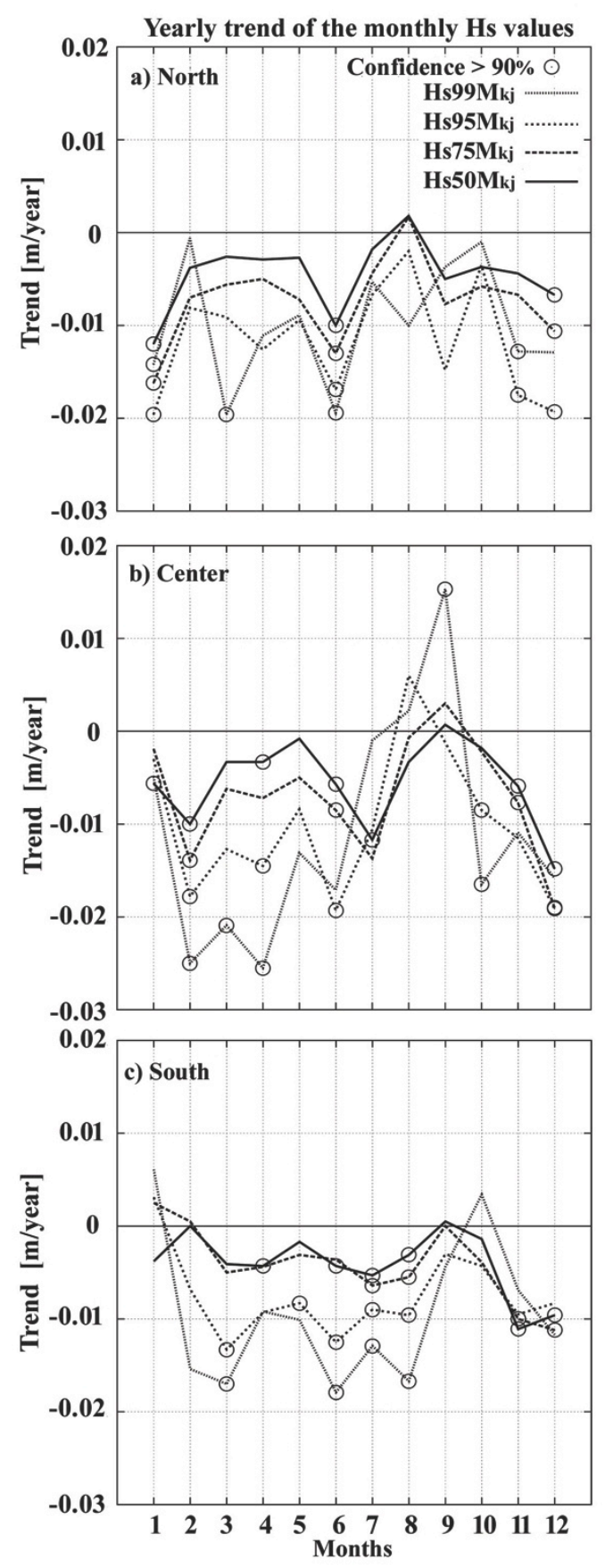

470 Figure 9 - For each of the three zones delimited in Figure 1, north to south from top to bottom: for each month of the year, 99, 95, 75, 50 percentiles of the long term trend of the significant wave height. A circle indicates that the result is significant at the $90 \%$ level. 

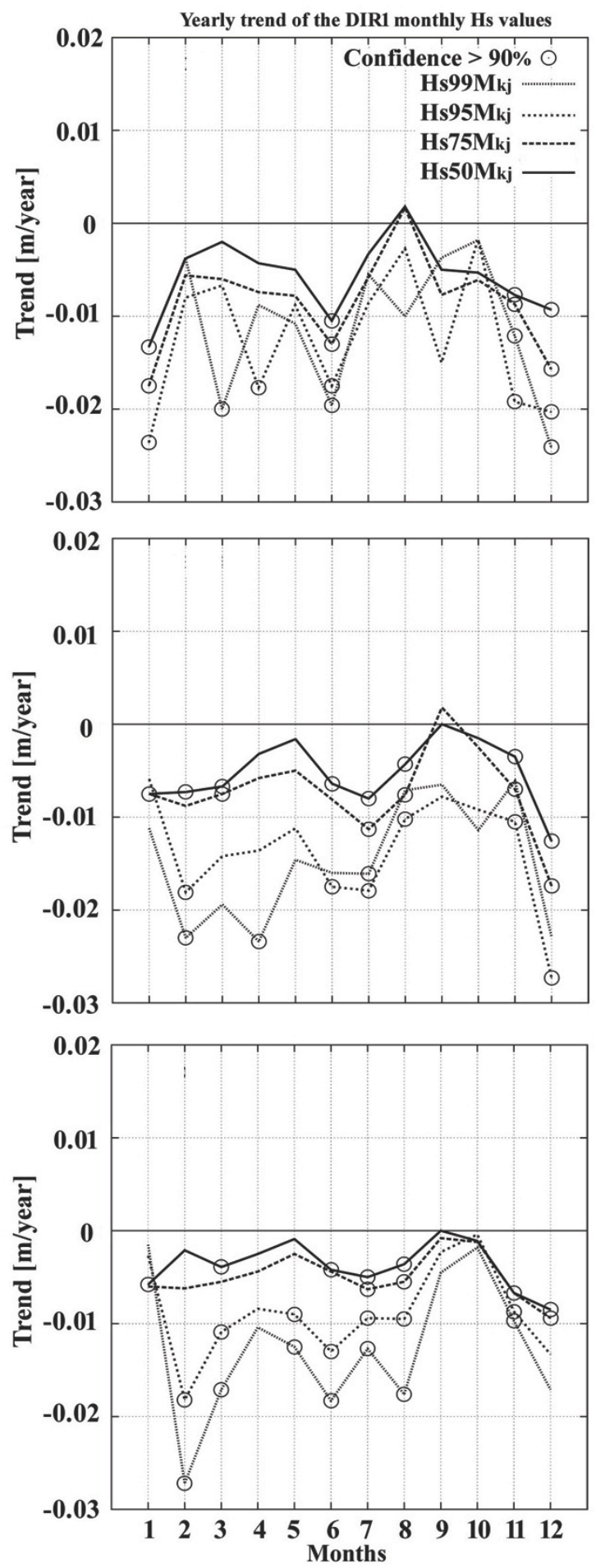

474 Figure 10 - As Figure 9, but for the south going waves in a $90^{\circ}$ sector centered on the main axis of the basin. 

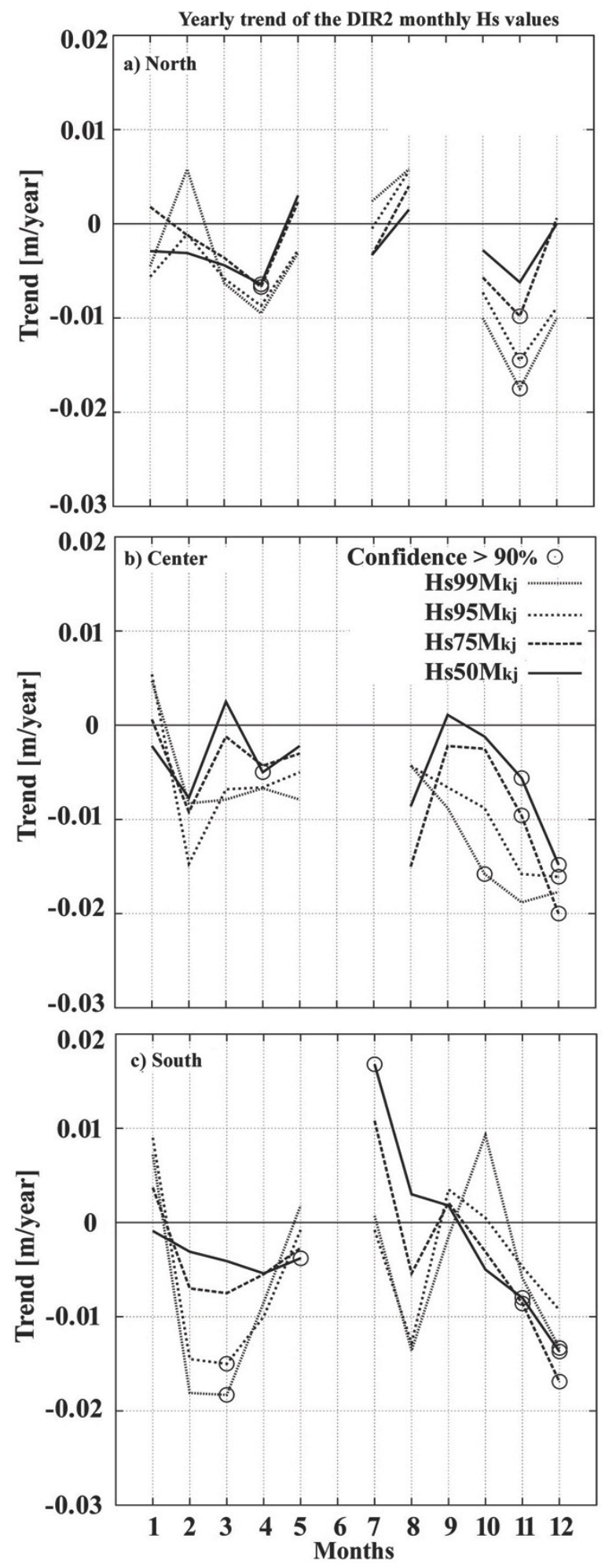

477 Figure 11- As Figure 9, but for the north going waves in a $90^{\circ}$ sector centered on the main axis of the basin. 